\title{
Experimental and analysis study on dispersion of phases in an Ebullated Bed Reactor
}

\author{
Mohammad F. Abid ${ }^{1, *}$, Zainab Y. Shanain ${ }^{1}$, and Kadhim N. Abed ${ }^{2}$ \\ ${ }^{1}$ Department of Chemical Engineering, University of Technology, P.O. Box 18310, Baghdad, Iraq \\ ${ }^{2}$ Directorate of Technical Education, Ministry of Education, Baghdad, Iraq
}

Received: 11 June 2018 / Accepted: 17 December 2018

\begin{abstract}
The effectiveness and performance of industrial hydro-processing Ebullated Bed Reactors (EBRs) are highly dependent on the bed hydrodynamics and operating conditions. In present work, hydrodynamics of EBRs was studied in a cold model experimental setup using air-water-solid particles system. Pressure gradient method and Residence Time Distribution (RTD) technique were used to estimate the individual holdups, and dispersion coefficients in the lab-scale ebullated bed column. System Hydraulic Efficiency (HEF) was also estimated. The results showed that liquid internal recycle ratio, which characterized the EBRs, has a predominant effect on the individual holdups and dispersion coefficients. Empirical correlations were developed for prediction of phase holdups, and dispersion coefficients with good accuracy.
\end{abstract}

\section{Nomenclature}

$A_{\mathrm{S}} \quad$ Cross-sectional area $\left(\mathrm{cm}^{2}\right)$

C Tracer concentration in liquid phase $(\mathrm{mg} / \mathrm{L})$

$d_{\mathrm{h}} \quad$ Distributor hole diameter $(\mathrm{mm})$

$D_{\text {axL }} \quad$ Liquid axial dispersion coefficient $\left(\mathrm{cm}^{2} / \mathrm{s}\right)$

$E \quad$ Exit age distribution function $(1 / \mathrm{s})$

$E_{\mathrm{b}} \quad$ Bed porosity (-)

$E_{\mathrm{G}} \quad$ Gas holdup in the dispersed bed (-)

$E_{\mathrm{L}} \quad$ Liquid holdup in the dispersed bed (-)

$E_{\mathrm{S}} \quad$ Solid holdup in the dispersed bed (-)

$g \quad$ Gravity force $\left(\mathrm{m} / \mathrm{s}^{2}\right)$

$H \quad$ Height of column $(\mathrm{cm})$

$H_{\mathrm{s}} \quad$ High of solid in the column $(\mathrm{cm})$

$L \quad$ Tested length of reactor $(\mathrm{cm})$

$M_{\mathrm{S}} \quad$ Mass of solid (kg)

$R \quad$ Recycle ratio (= recycle liquid flow rate/fresh feeding liquid flow rate)

$t \quad$ Time (s)

$t_{\mathrm{m}} \quad$ Mean residence time (s)

$u_{\mathrm{L}} \quad$ Superficial liquid velocity at column inlet after mixing $\left(=u_{\text {Lo }}(1+R)\right)(\mathrm{cm} / \mathrm{s})$

$u_{\text {Lo }} \quad$ Superficial liquid velocity of fresh feed (at $R=0$ ) $(\mathrm{cm} / \mathrm{s})$

$u_{\mathrm{G}} \quad$ Superficial gas velocity $(\mathrm{cm} / \mathrm{s})$

$V_{\mathrm{b}} \quad$ Volume of the bed $\left(\mathrm{cm}^{3}\right)$

* Corresponding author: 80005@uotechnology.edu.iq
$V_{\mathrm{p}} \quad$ Volume of the particles $\left(\mathrm{cm}^{3}\right)$

$V_{\mathrm{R}} \quad$ Reactor volume $\left(\mathrm{cm}^{3}\right)$

\section{Greek symbols}

$\rho_{\mathrm{g}} \quad$ Density of gas $\left(\mathrm{kg} / \mathrm{m}^{3}\right)$

$\rho_{\mathrm{l}} \quad$ Density of liquid $\left(\mathrm{kg} / \mathrm{m}^{3}\right)$

$\rho_{\mathrm{s}} \quad$ Density of solid $\left(\mathrm{kg} / \mathrm{m}^{3}\right)$

$\mu_{1} \quad$ Liquid viscosity (mPa s)

$\mu_{\mathrm{g}} \quad$ Gas viscosity (mPa s)

$\sigma \quad$ Gas-liquid surface tension $\left(\mathrm{kg} / \mathrm{s}^{2}\right)$

$\triangle P \quad$ Pressure drop $(\mathrm{kPa})$

$\sigma^{2} \quad$ Variance $\left(\mathrm{s}^{2}\right)$

\section{Introduction}

The Ebullated Bed Reactor (EBR), shown in Figure 1, plays a significant function in the developing of hydroconversion processes. The reactor is considered as a continuous flow three-phase (gas-liquid-solid) bubble column. The packing of catalyst is distinguished by little pressure drop decline, blocked-free, and a good mixing between oil and particles which behaving like a complete back-mixed reactor. A major merit of the EBR is the removal and make-up of the catalyst particles from time to time without 


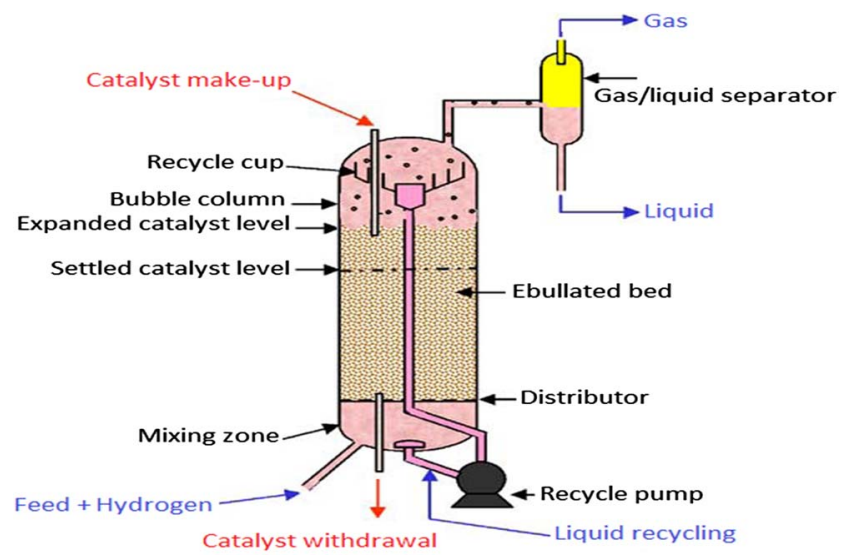

Fig. 1. Schematic of the Ebullated Bed Reactor (EBR) (Kressmann et al., 2000).

upsetting the continuous operation (Kressmann et al., 2000). The amelioration of this process and the technology need a reliable and proven method for a better understanding of process hydrodynamics. Residence Time Distribution (RTD) test is an effective gadget tool that can be utilized to examine the deficiency of chemical reactors. It can also be advantageous in designing reactor. This procedure is, thus, also significant in educate reaction engineering for non-ideal reactors (Froment et al., 2010). This simple route to measure the quantity of mixing is suitable to combine kinetics in the estimation of reactor is classically conducted by utilizing RTD studies (Fogler, 1999).

van Gelder and Westerterp (1990) carried out an impulse tracer experiments in a co-current up flow fixed-bed reactor for $\mathrm{CH}_{3} \mathrm{OH} / \mathrm{H}_{2}$ system at low superficial velocities $\left(u_{\mathrm{L}}=0.02-0.15 \mathrm{~mL} / \mathrm{min}\right.$ and $\left.u_{\mathrm{G}}=0.49-14.33 \mathrm{~mL} / \mathrm{min}\right)$, and at higher pressure $(0.2-1.2 \mathrm{MPa})$. The mixing characteristics were described by estimation of the axial dispersion. They utilized the method of weighted moments to evaluate the parameters. They used various kinds of mathematical relations for the Bodenstein number and fluid holdup. From these mathematical relations, the optimal one was chosen for each variable. They concluded that the weighted moments method were more reliable than the ordinary moments. Kressmann et al. (2000) conducted an RTD study using a radioactive tracer on a lab-scale unit of EBR. These experiments measured the quantity of the hydrodynamics and the fluid holdup in the reactor. Authors reported that these variables are safely securing an extrapolation of the pilot plant results. Schweitzer and Kressmann (2004) developed an unsteady-state model for non-isothermal operated catalytic reactor involving hydrodynamics and kinetics. For validation of the formulated model, a lab-scale reactor was operated under industrial conditions with radioactive tracer test for RTD measurements. Authors reported a good agreement between their model and experimental results. Sánchez et al. (2005) studied the hydrodynamic characteristics and gas-liquid mass transfer in a laboratory scale inverse turbulent bed reactor. They utilized the RTD in order to characterize internal flow in the reactor. Different solid hold-up (0-0.37) and air superficial velocity
$(2.7-6.5 \mathrm{~mm} / \mathrm{s})$ values were assayed in RTD experiments. Authors formulated a model that represented the hydrodynamic of the inverse turbulent bed considering the reactor as two-mixed tank of different volumes in series. Sánchez et al. revealed that the value of the volumetric gas-liquid mass transfer coefficient $\left(k_{L} a\right)$ was independent of the solid hold-up. Pjontek and Macchi (2014) performed experiments to validate the use of two sizes of glass spheres and cylindrical with diameters of 4 and $1.5 \mathrm{~mm}$ when investigating the global hydrodynamic features of a co-current gas-liquid-solid fluidized bed. Authors reported that high gas holdup conditions were obtained by increasing the system pressure to $6.5 \mathrm{MPa}$ and/or adding a surfactant. The experiments were conducted in a $101.6 \mathrm{~mm}$ diameter column and a maximum expanded bed height of $1.8 \mathrm{~m}$ with tap water or a 0.5 wt. $\%$ aqueous ethanol solution as the liquid phase. Global phase holdups measured from the dynamic pressure profiles characterized the hydrodynamic behavior of the fluidized bed and the standard deviations of the mean holdups aided the comparison and also examined the fluctuations of the bed interface. Liquid-solid fluidized bed experiments demonstrated that equivalent Sauter mean diameters resulted in comparable bed porosities. Authors found that gas-liquid-solid fluidized bed dynamics of equivalent size spherical and cylindrical particles were similar in the dispersed bubble flow regime whereas differences were observed in the presence of larger coalescing bubbles. Parisien et al. (2017) conducted experiments to investigate the impact of a wide particle density distribution on gas-liquid-solid fluidized beds phase holdups and bed behavior when operating under high gas holdup conditions relevant to the EBR. The experiments were performed at ambient temperature and pressure in a clear polyvinyl chloride column with a maximum expanded bed height of $2.7 \mathrm{~m}$ and an inner diameter of $0.152 \mathrm{~m}$. The range of operating conditions was $\left(u_{\mathrm{Lo}}=0-47 \mathrm{~mm} / \mathrm{s}, u_{\mathrm{G}}=0-45 \mathrm{~mm} / \mathrm{s}\right.$, $P=104 \mathrm{kPa})$. A 0.5 wt.\% aqueous ethanol solution was used to obtain relatively high gas holdups as observed in many industrial reactors containing liquid mixtures with surface-active compounds. Authors reported that at elevated liquid flow rates, the bed interface became more stable due to smaller bubbles being formed because of the greater shear stress at the gas-liquid distributor. Solid holdup was the most affected by the particle density distribution, where bed expansion/contraction was dependent of the liquid flow rate due to varying particle-bubble dynamics. Authors indicated that such information provided guidance on potential factors that can lead to the loss of bed-freeboard interface in the operation of heavy oil hydroprocessors such as the LC-Finer ${ }^{\mathrm{SM}}$. Shah et al. (2012) studied extensively the gas holdup, axial liquid dispersion, and mass transfer in packed, trayed, and empty bubble columns. They revealed that the gas holdup and mass transfer characteristics of the packed and trayed bubble columns are superior to those of an empty bubble column, while the axial dispersion coefficients are much lower. Shah et al. correlated the experimental data of the different types of bubble columns by dimensionless number, Bodenstein number (for axial dispersion coefficient), and Stanton number (for the volumetric mass transfer coefficient), as a function of the 
Froude and Galileo dimensionless numbers. The present study aimed to investigate hydrodynamic characteristics (e.g., holdups of phases and liquid axial dispersion) of a cold lab-scale EBR using the RTD technique and pressure measurements. Another objective was to formulate empirical correlations for the hydrodynamic parameters as a function of the studied operating variables (e.g., internal recycle ratio, and superficial velocities of liquid and gas).

\section{Theoretical aspects}

Pressure drop measurement was used to determine individual holdups (i.e., $E_{\mathrm{g}}, E_{1}$ and $E_{\mathrm{s}}$ ). The pressure drop could be correlated to the density of the fluid phases,

$$
\Delta P=g \Delta H_{\mathrm{s}}\left(\rho_{\mathrm{g}} E_{\mathrm{g}}+\rho_{\mathrm{l}} E_{\mathrm{l}}+\rho_{\mathrm{s}} E_{\mathrm{s}}\right) .
$$

The solids hold-up can be estimated using equation (2):

$$
E_{\mathrm{s}}=\frac{M_{\mathrm{s}}}{A_{\mathrm{s}} \Delta H_{\mathrm{s}} \rho_{\mathrm{s}}} .
$$

Equation (3) represents the phases existed in the reactor, then;

$$
E_{\mathrm{g}}+E_{\mathrm{l}}+E_{\mathrm{s}}=1 .
$$

Equations (1)-(3) were solved for the three phase holdups at various heights along the column:

$$
\begin{gathered}
E_{\mathrm{g}}=\frac{\rho_{\mathrm{l}}-E_{\mathrm{s}} \rho_{\mathrm{l}}-\frac{\Delta p}{H_{\mathrm{s}}}+E_{\mathrm{s}} \rho_{\mathrm{s}}}{\rho_{\mathrm{l}}-\rho_{\mathrm{g}}}, \\
E_{\mathrm{l}}=1-E_{\mathrm{s}}-\frac{\rho_{\mathrm{l}}-E_{\mathrm{s}} \rho_{1}-\frac{\Delta p}{H_{\mathrm{s}}}+E_{\mathrm{s}} \rho_{\mathrm{s}}}{\rho_{\mathrm{l}}-\rho_{\mathrm{g}}} .
\end{gathered}
$$

The dispersion coefficient was calculated using the RTD test from experimental data.

Mean residence time $\left(t_{\mathrm{m}}\right)$ was estimated using equation (6) (Saroha and Khera, 2006):

$$
t_{\mathrm{m}}=\frac{\int_{0}^{\infty} t_{\mathrm{i}} C_{\mathrm{i}} \mathrm{d} t}{\int_{0}^{\infty} C_{\mathrm{i}} \mathrm{d} t} \cong \frac{\sum t_{\mathrm{i}} C_{\mathrm{i}} \Delta t}{\sum C_{\mathrm{i}} \Delta t}=\int_{0}^{\infty} t E(t) \mathrm{d} t
$$

where $E(t)$ is RTD function evaluated by equation (7) (Fogler, 1999):

$$
E(t)=\frac{C_{\mathrm{i}}}{\int_{0}^{\infty} C_{\mathrm{i}} \mathrm{d} t} \cong \frac{C_{\mathrm{i}}}{\sum C_{\mathrm{i}} \Delta t} .
$$

Liquid axial dispersion coefficient $\left(D_{\text {axl }}\right)$ was estimated in terms of liquid Peclet number $\left(\mathrm{Pe}_{\mathrm{L}}\right)$ by equation (8) (Chander et al., 2001; Fogler, 1999; Levenspiel, 1999):

$$
\frac{\sigma_{\mathrm{i}}^{2}}{\left(t_{\mathrm{m}}\right)^{2}}=\frac{2}{P e_{\mathrm{L}}}\left(\mathrm{Pe}_{\mathrm{L}}-1+e^{-\mathrm{Pe}_{\mathrm{L}}}\right)
$$

where,

$$
\begin{gathered}
\mathrm{Pe}_{\mathrm{L}}=\frac{u_{\mathrm{L}} L}{D_{\mathrm{axL}}}, \\
u_{\mathrm{L}}=u_{\mathrm{Lo}}(1+R),
\end{gathered}
$$

$u_{\mathrm{Lo}}$ : liquid superficial velocity of fresh feed (without mixing with recycle liquid),

$u_{\mathrm{L}}$ : liquid superficial velocity at inlet of column (after mixing with recycle liquid).

$$
\sigma_{\mathrm{i}}^{2}=\frac{\int_{0}^{\infty} t_{\mathrm{i}}{ }^{2} C_{\mathrm{i}} \mathrm{d} t}{\int_{0}^{\infty} C_{\mathrm{i}} \mathrm{d} t}-\left(t_{\mathrm{m}}\right)^{2} \cong \frac{\sum{t_{\mathrm{i}}}^{2} C_{\mathrm{i}} \Delta t}{\sum C_{\mathrm{i}} \Delta t}-\left(t_{\mathrm{m}}\right)^{2}
$$

Thackston et al. (1987) reported that a function called as the Hydraulic Efficiency (HEF) could be used to quantify the allocation and mixing of fluids inside the reactor, expressed by equation (12):

$$
\mathrm{HEF}=\gamma_{\mathrm{V}} \cdot \gamma_{\mathrm{RTD}},
$$

$\gamma_{\mathrm{V}}$, and $\gamma_{\mathrm{RTD}}$ are system volumetric efficiency and efficiency of RTD respectively.

$$
\begin{gathered}
\gamma_{\mathrm{V}}=\frac{t_{\mathrm{m}}}{\tau}, \\
\gamma_{\mathrm{RTD}}=1-\sigma_{\theta}^{2}, \\
\sigma_{\theta}{ }^{2}=\frac{\sigma^{2}}{t_{\mathrm{m}}^{2}},
\end{gathered}
$$

where $\sigma_{\theta}{ }^{2}$ and $\sigma^{2}$ are system dimensionless variance and tracer flow variance respectively.

Percentage stagnant regions in the reactor $\left(Z_{\mathrm{d}}, \%\right)$ could be calculated using equation (16) (Sarathai et al., 2010):

$$
Z_{\mathrm{d}}(\%)=\left(1-\frac{t_{\mathrm{m}}}{\tau}\right) \times 100,
$$

where $\tau$ is the Nominal residence time $=\frac{\text { volume of reactor }}{\text { volumetric flow rate }}$.

\section{Experimental}

\subsection{Material}

Sodium chloride $(\mathrm{NaCl})$ obtained from Merck and was used for conductivity measurements. $\mathrm{CoMo} / \mathrm{Al}_{2} \mathrm{O}_{3}$ catalyst (particle density $\left(\rho_{\mathrm{s}}\right), 1.7 \mathrm{~g} / \mathrm{cm}^{3}$; particle diameter, $2.5 \mathrm{~mm}$ (sphericity, 0.803); particle length, $5 \mathrm{~mm}$; bed porosity, 0.8 ; interfacial area, $180 \mathrm{~m}^{2} / \mathrm{g}$; volume of pore, $0.5 \mathrm{~mL} / \mathrm{g}$ ) supplied from Al-Daura Oil Refinery in Baghdad city, and was used as a solid bed. Pre-filtered air was used as the gas phase. Other facilities and equipment used for experimental setup and process measurements are shown in Table 1. 
Table 1. Equipment used in the experimental setup.

\begin{tabular}{ll}
\hline Item & Description \\
\hline Column & $(72 \mathrm{~mm} \mathrm{i.d} \times 1600 \mathrm{~mm}$ long), Plexiglas \\
Feeding pump & Centrifugal $(\mathrm{KSB})$, flow rate $=1 \mathrm{~m}^{3} / \mathrm{h}$, head $=20 \mathrm{~m}$, carbon steel \\
Recycle pump & Centrifugal $(\mathrm{KSB})$, flow rate $=5 \mathrm{~m}^{3} / \mathrm{h}$, head $=25 \mathrm{~m}$, carbon steel \\
Feeding tank & Volume $=100 \mathrm{~L}, \mathrm{PVC}$ \\
Pressure gauge & Bourdon type gauge, 4 inch dial, $0-200 \mathrm{mbar}$, stainless steel \\
Gas flow meter & Floating type flowmeter, $0-800 \mathrm{~L} / \mathrm{min}$, glass made \\
Flow meter for fresh liquid & Floating type flowmeter, $0-40 \mathrm{~L} / \mathrm{min}$, glass made \\
Flow meter for recycle liquid & Floating type flowmeter, $0-4000 \mathrm{~L} / \mathrm{h}$, glass made \\
\hline
\end{tabular}

(a)
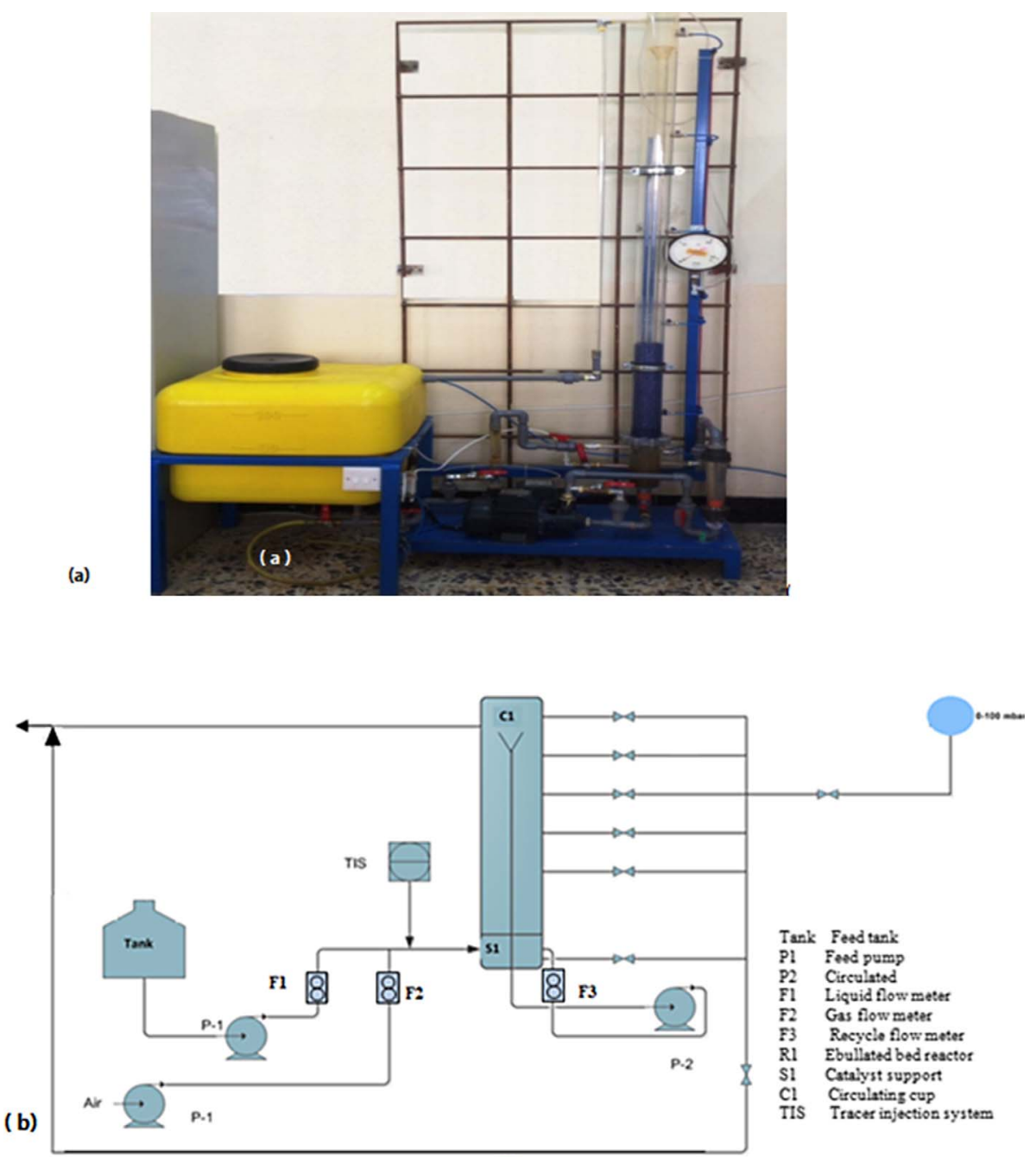

Fig. 2. (a) Photographic view of the experimental setup; (b) schematic of the apparatus setup.

\subsection{Experimental setup}

The experimental setup is composed of a Plexiglas column equipped with six sampling taps located axially along the column; feed tank; two centrifugal pumps are used one for fresh feed and the other for liquid circulation as shown in Figures $2 \mathrm{a}$ and $2 \mathrm{~b}$. The feeding of liquid and air was at the bottom of column through a mixing chamber beneath a distributor grid $(8.6 \mathrm{~cm} \mathrm{OD} \times 2 \mathrm{~mm}$ thickness) made of a stainless steel 316 perforated with 31 holes $\left(d_{\mathrm{h}}=1.0 \mathrm{~mm}\right)$. 
(a)

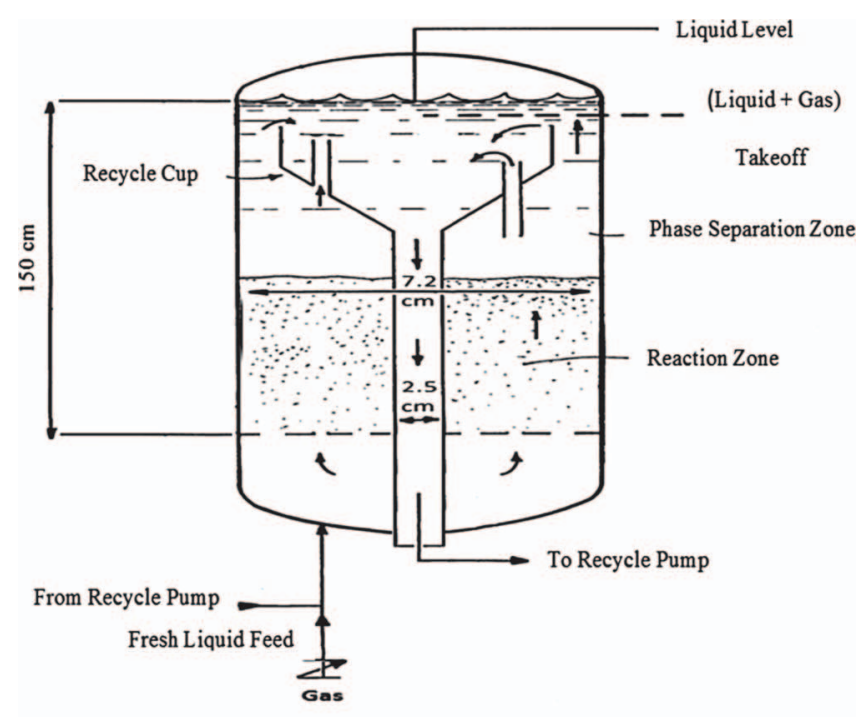

(b)
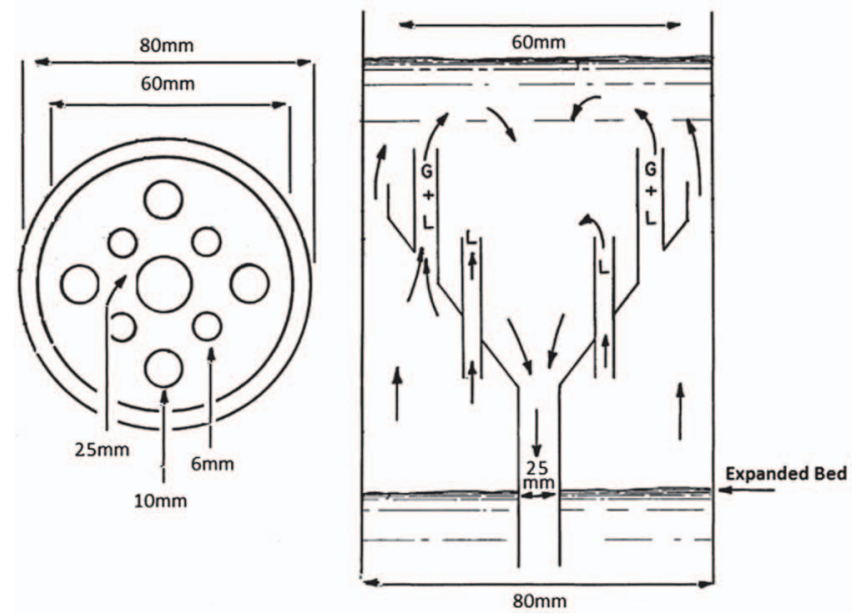

Fig. 3. Details of column internals. (a) Schematic diagram of the cold lab-scale ebullated bed column; (b) details of the recycle cup.

Packings of ceramic and plastic raschig were placed into the mixing chamber to enhance the distribution of liquid and gas. A compressor was used to supply deoiled air to the column. The feeding gas and liquid are regulated via calibrated flow meters for the gas (F2) and the liquid (F1) respectively. The bed expansion is controlled by the flow of liquid, which is conducted by pumping recycle liquid returned in a recycle cup at the upper part of the reactor by an elongated return line of $25 \mathrm{~mm}$ in diameter located within the reactor vessel connected to the suction of the recycling pump (P2). Details of the column internals are shown in Figure 3. At the top of the column, a two-phase flow of air and liquid were discharged out of the system. Water is used, as the continuous phase. All the sampling taps were connected to a three-way valve which facilitates the use of the taps either for pressure measurement (connected to a pressure manometer, 0-200 mbar) or via a selector valve to a $\mathrm{WTW}^{\circledR}$ Laboratory conductivity meter type inoLab ${ }^{\circledR}$ Cond 7310 for liquid conductivity measurement. For RTD experiments, an input pulse of tracer was inserted into the liquid stream at the inlet to the column using the injector configuration shown in Figure 4 which consists of a needle feeding valve for the pressurized gas, two ball valves, one for the tracer injection, and the other for release of the pressurized gas; two non-return valves to prevent the backflow of tracer into the injector, and a pressure gauge to indicate the pressure inside the injector. The calibration of the conductivity meter was done by using standard $\mathrm{NaCl}$ solutions prepared for this process. Figure 5 shows the calibration of conductivity against $\mathrm{NaCl}$ concentration. Ranges of operating variables (i.e., superficial velocities of gas and liquid, recycle ratio, and initial concentration of tracer) used in the present work are listed in Table 2. 


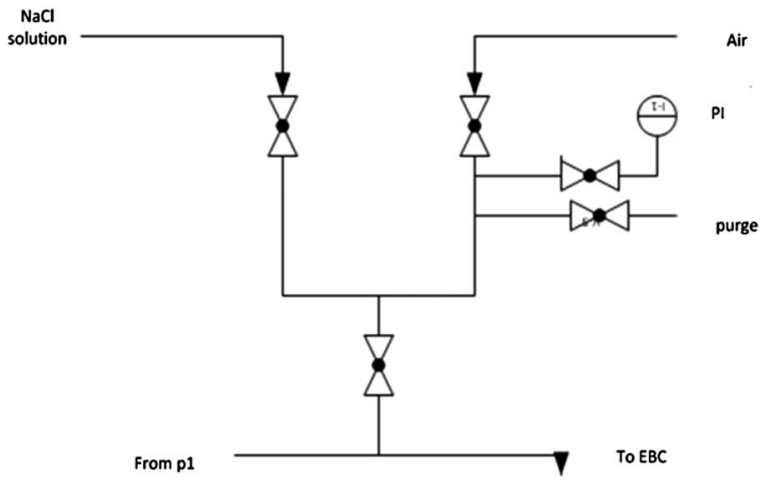

Fig. 4. Schematic of the injection system.

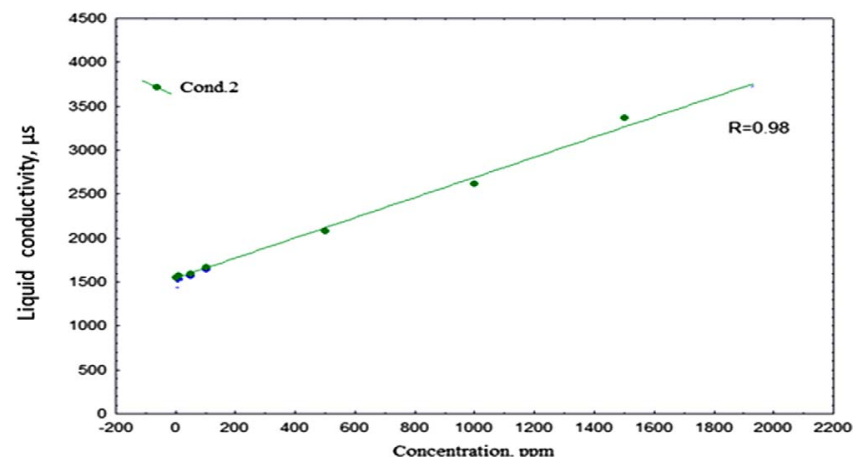

Fig. 5. Calibration curve of solution conductivity against $\mathrm{NaCl}$ concentration.

Table 2. Ranges of operating variables.

\begin{tabular}{lc}
\hline Operating variable & Range \\
\hline Gas superficial velocity $\left(u_{\mathrm{G}}\right), \mathrm{cm} / \mathrm{s}$ & $1-10$ \\
Liquid superficial velocity $\left(u_{\mathrm{Lo}}\right), \mathrm{cm} / \mathrm{s}$ & $1-6$ \\
Recycle ratio $(R)$ & $1-5$ \\
Initial concentration of injected $\mathrm{NaCl}, \mathrm{ppm}$ & $100-1000$ \\
Temperature, ${ }^{\circ} \mathrm{C}$ & $25 \pm 1{ }^{\circ} \mathrm{C}$ \\
Pressure, barg. & 1.2 \\
\hline
\end{tabular}

\section{Results and discussion}

\subsection{Effect of the gas and liquid superficial velocities on holdups}

Figures $6 \mathrm{a}$ and $6 \mathrm{~b}$ illustrate the effects of the gas and liquid superficial velocities on the average value of liquid and solid holdups (i.e., $E_{\mathrm{L}}$ and $E_{\mathrm{S}}$ ). As can be seen in Figure 6a, liquid holdup increases gradually with increasing gas velocity at all conditions which can be attributed to the bed expansion due to the increase in intensity of liquid turbulence. However, Figure $6 \mathrm{~b}$ shows a different trend as solid holdup decreases with increasing liquid velocity to compensate for the increased gas and liquid holdups in the bed.

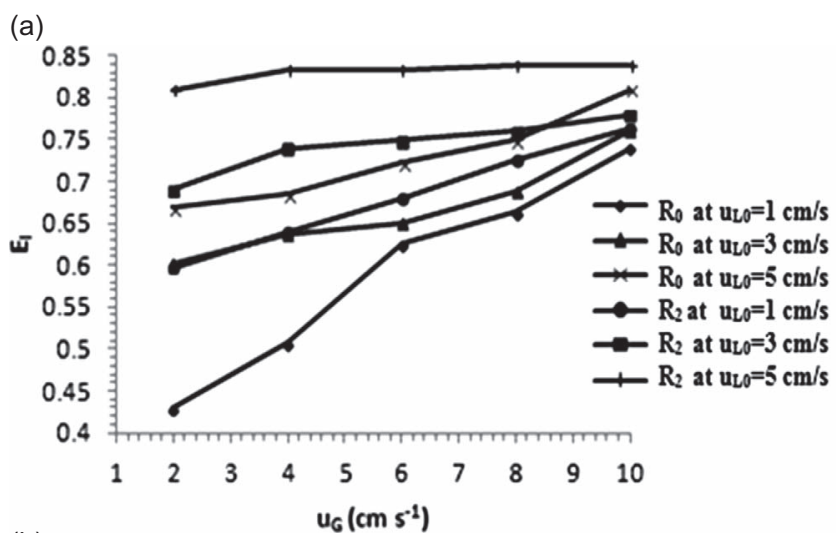

(b)

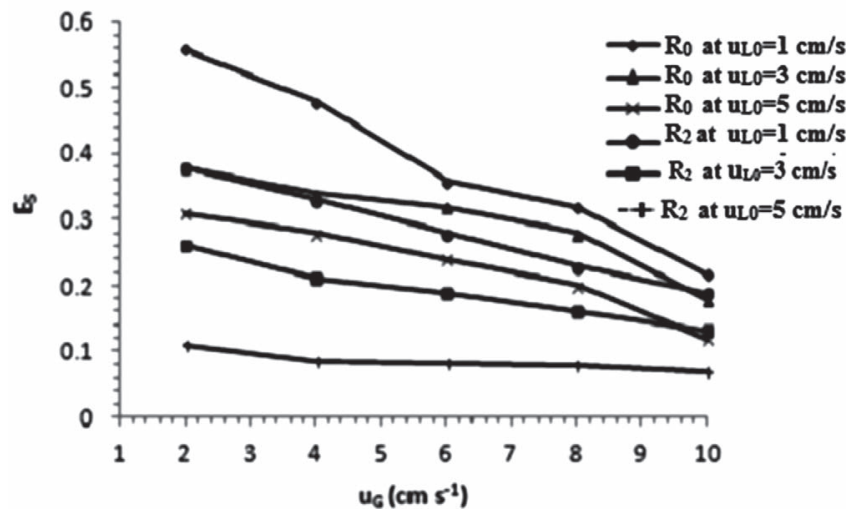

Fig. 6. (a) Variation of liquid holdup with gas and superficial liquid velocities at different $R$; (b) variation of solid holdup with gas and liquid superficial velocities at $R$.

Figures $6 \mathrm{a}-6 \mathrm{~b}$ also show the effect of internal recycle ratio on individual holdups. Liquid flow rate in the bed increases with increasing internal recycle ratio and therefore similar trend would be expected as caused by increasing liquid velocity. However the recycle ratio impact is less severe at higher liquid velocities as the large portion of the bed has been already occupied by the liquid phase. Interestingly, at $R=0$ the rates of increase in liquid holdup and decrease in solid hold up are higher at lower gas and liquid velocities, therefore operations at higher liquid and gas velocities may have a negative impact on the overall reaction rate due to decrease in residence time and contact with catalyst particles. However, as can be seen in Figures $6 \mathrm{a}$ and $6 \mathrm{~b}$, when $R$ increased one could operate the reactor at lower velocities of fresh liquid and may obtaining the same required conversion. These results depict that internally recycle ratio has a predominant effect on bed porosity more than fresh feed flow rate. The bed becomes more turbulent at higher liquid velocities, which induces better mixing and reduction in mass transfer resistances (due to dispersion enhancement) in favor of reaction efficiency. On the other hand, the residence time for gas and liquid would decrease, which may have a negative impact on the conversion. However, this effect may be equalized by the influence of the internal recycle ratio. High liquid velocity has a pronounced effect on the holdups of liquid and solid as compared to gas velocity due to its much higher viscosity and density resulting in a larger 
bed expansion, especially at high gas flow rates. However, the effect of gas velocity is higher at low liquid velocities as shown in Figures 6a and 6b. Trend of the present results was confirmed by the experimental outcomes of Shin et al. (2007) and Pjontek, (2014), although Sivalingam and Kannadasan (2009) reported a different trend for the effect of fluid flow rates on liquid holdups in co-current three phase fluidized beds.

\subsection{Dispersion parameters}

RTD tests were conducted to investigate the mixing behavior of the EBR. The hydrodynamic characteristics were studied using the pulse input tracer test. Figure 7 shows the obtained RTD curves for the system working at a constant superficial velocity $\left(u_{\mathrm{Lo}}\right)=5 \mathrm{~cm} / \mathrm{s}$ and various air velocities $(1,3$ and $5 \mathrm{~cm} / \mathrm{s}$ ) with $R=0$ and also with $R=2$ at column high $(H)$ of $60 \mathrm{~cm}$. For comparison of various systems, the $C-t$ curves were normalized, to generate what is called $E$ curves using equation (7). It can be seen in Figure 7 that the trends of all curves were identical. On the onset, they have a summit after then it vanishes continuously. These curves represent a system of good mixing flow mode. It is shown that as the velocities of air increase, the concentration of tracer increases correspondingly. This is due to the decrease in the holdup of liquid. As can be observed in Figure 7, the time span between the peaks is small. However, as gas velocity increases the Figure shows faster peaks. For $R=2$, the output response shows successive peaks. The first peak monitored by the conductivity probe points out the progress of the pulsation through the reactor. The other peaks may be because of the tracer re-injected by means of the recycle line which affirms the existence of $\mathrm{NaCl}$ in the liquid phase. These several peaks are exemplary indications created from a recirculating system (Levenspiel, 1999). The successive peaks are damped progressively because of the lessening of the tracer at the exit of the test section specified by the open system.

Figure 8 illustrates the influence of liquid superficial velocity on liquid Peclet number for present work and that of Essadki et al. (2011) who studied the hydrodynamics of the liquid circulation induced by hydrogen microbubbles bubbles in an external-loop airlift reactor using RTD measurements. The superficial liquid velocity used by Essadki et al. (2011) in the riser section was $\left(u_{\mathrm{Lo}}=\right.$ $0-4 \mathrm{~cm} / \mathrm{s}$ ). Figure 8 shows that as the liquid velocity raised up, the deviation from plug flow rises. One may deduce that dispersion is favored in the segregation zone showing an increase in the turbulence intensity as liquid velocity increased. The same trend for $\mathrm{Pe}_{\mathrm{L}}$ against superficial liquid velocity is observed in Figure 8 for present work and that of Essadki et al. (2011). It can be seen that for all the cases, gas velocity and internal recycle ratio have pronounced effect on axial dispersion. According to the outcomes of RTD tests and Peclet numbers, it is possible to conclude that the EBR approaches flow pattern which is intermediate between completely mixed and moderate back-mixing at the studied internal recycle ratio, liquid flow rate and gas velocities.

Table 3 lists estimated values of liquid longitudinal dispersion coefficient as a function of operating parameters.

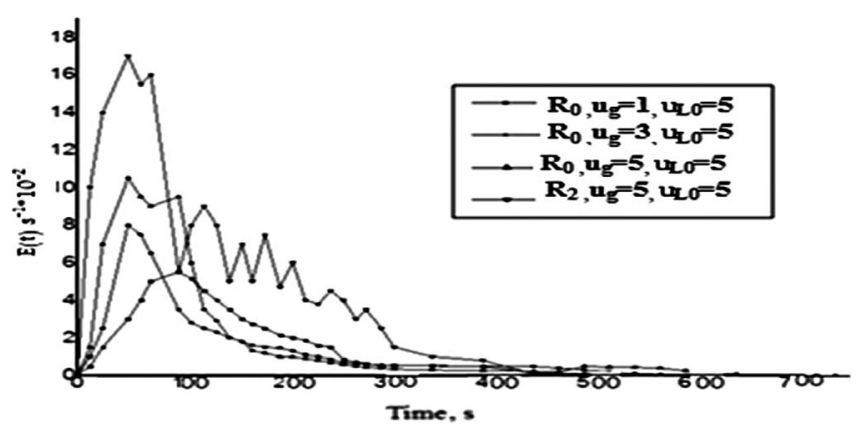

Fig. 7. $E$ curves for air-water-solid system at various liquid and gas superficial velocities.

As can be observed in this Table, that gas superficial velocity and internal recycle ratio offered the predominate effect on back-mixing parameter in EBRs. Data in Table 4 were utilized to obtain an empirical correlation which connects the longitudinal dispersion coefficient with the studied operating parameters.

Figure 9 shows a comparison in dispersion coefficient of present work with the published works of Kim and Kim (1983), and Silva (2001) who worked on three phase fluidized bed columns with air-water-solid particles systems. For Figure 9, the operating conditions used by Kim and Kim (1983) are liquid velocity $\left(u_{\mathrm{Lo}}=2 \mathrm{~cm} / \mathrm{s}\right)$, gas velocity $\left(u_{\mathrm{G}}=0-8 \mathrm{~cm} / \mathrm{s}\right)$, glass particle size $(1.7 \mathrm{~mm})$ and column diameter $(14.5 \mathrm{~cm})$ while that used by Silva (2001) are liquid velocity $\left(u_{\mathrm{Lo}}=1.3 \mathrm{~cm} / \mathrm{s}\right)$, gas velocity $\left(u_{\mathrm{G}}=0-2.4 \mathrm{~cm} / \mathrm{s}\right)$, polystyrene particle size $(2.2 \mathrm{~mm})$ and column diameter $(6.3 \mathrm{~cm})$. As listed in Table 3, our operating conditions used in Figure 9 are liquid velocity $\left(u_{\mathrm{Lo}}=3 \mathrm{~cm} / \mathrm{s}\right)$, and gas velocity $\left(u_{\mathrm{G}}=0-8 \mathrm{~cm} / \mathrm{s}\right)$. As can be observed from Figure 9 , that under the same operating systems (i.e., air-watersolid), the superficial velocities of fluids play an effective role on dispersion coefficients.

\subsection{System Hydraulic Efficiency (HEF)}

Terashima et al. (2009) reported that HEF is associated with the usable volume and flow mode; hence on the one hand, it is related to the reactor performance, and on the other hand, it is affected by hydrodynamic parameters. Persson et al. (1999) classified the HEF into three groups: good $(\mathrm{HEF}>0.75)$, fair $(0.75 \leq \mathrm{HEF} \geq 0.50)$ and poor $(\mathrm{HEF} \leq 0.50)$. Table 4 depicts a set of data, including $\mathrm{HEF}$ and stagnant zones as a function of operating conditions that has been concluded from Figures 7, 8 and Table 3 . As can be observed in Table 4, the HEF of EBR at 11.3, $10.1,9.4$ and $5 \mathrm{~s}$ was $0.84,0.81,0.8$ and $0.76 \mathrm{~s}$, respectively. The HEF bounded under the group of good in all the retention times. This may be attributed to the mixing mode which has a serious effect on the HEF. According to Levenspiel (1999), back-mixing is one of the important parameters which decide the performance of the reactor. When the reactor approaches a single CSTR (Continuous Stirred Tank Reactor), it has a large dispersion number $\left(\mathrm{D} / u_{\mathrm{L}} \mathrm{L} \geq 0.2\right)$ implying a high degree of longitudinal mixing, which was noticed in EBR with a less retention time of 


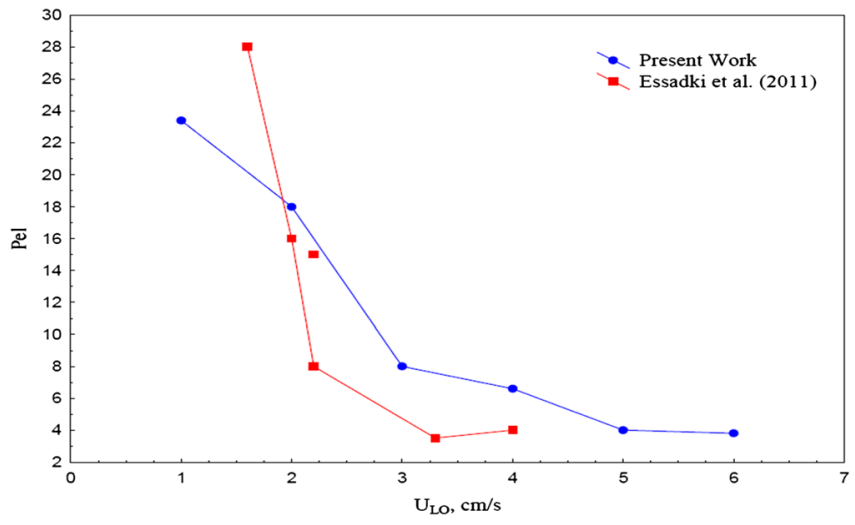

Fig. 8. Variation of liquid Peclet number against liquid superficial velocity.

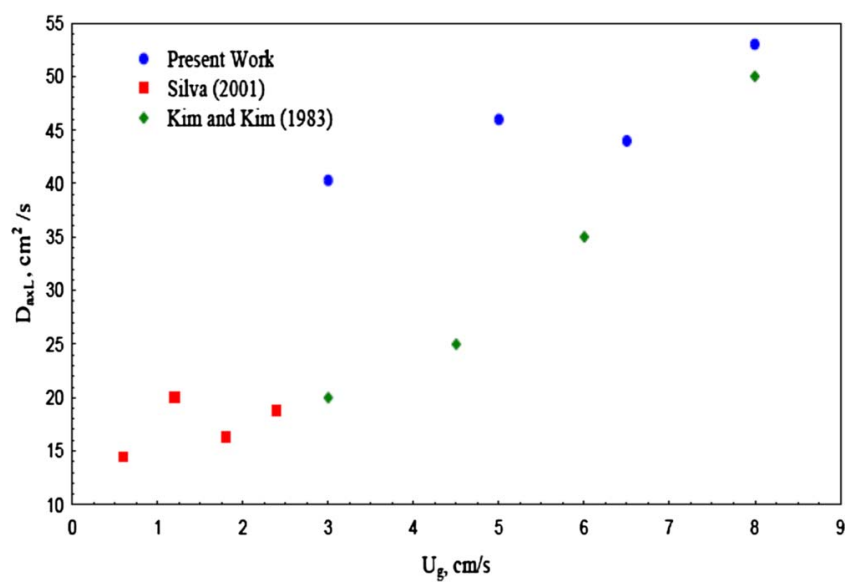

Fig. 9. Variation of dispersion coefficient against gas velocity at constant liquid velocity.

$5 \mathrm{~s}$. The axial dispersion (back-mixing) becomes relatively lesser in the residence time of 9.4 and $11.3 \mathrm{~s}$ with dispersion numbers in the range $0.02 \leq \mathrm{D} / u_{\mathrm{L}} \mathrm{L} \leq 0.2$ which is equivalent to $5 \leq \mathrm{Pe}_{\mathrm{L}} \leq 100$, showing that the flow pattern is intermediate between completely mixed and moderate back-mixing. This conclusion is confirmed by data illustrated in Figure 8. As can be shown in Figure 8 that as the liquid velocity increased from 1 to $6 \mathrm{~cm} / \mathrm{s} \mathrm{Pe}_{\mathrm{L}}$ varies from 23.7 to 4.6. However, Kressmann et al. (2000) have also considered $\mathrm{Pe}_{\mathrm{L}}$ number as a useful parameter for fitting the data of their bench reactor to the dispersed plug flow model. The stagnant (or dead) zone is a function of flow rate and number of compartments inside the reactor (Tsai et al., 2012). Because of decreasing residence time $(5.0 \mathrm{~s})$, more mixing in the reactor occurs. In the case of EBR, the dead space increased from $5 \%$ to $20 \%$ for $t_{\mathrm{m}} 11.3-5 \mathrm{~s}$; this may be due to the solid phases that are loosely dispersed inside the reactor, which helped in mixing of the tracer.

\subsection{Empirical correlations}

The values of the average liquid holdup, solid holdup bed porosity, and liquid axial dispersion, in ebullated bed
Table 3. Parameters of flow mode for air-water-solid system in the ebullation reactor.

\begin{tabular}{lccc}
\hline$u_{\mathrm{G}}\left(\mathrm{cm} \mathrm{s}^{-1}\right)$ & $u_{\mathrm{Lo}}\left(\mathrm{cm} \mathrm{s}^{-1}\right)$ & $R$ & $D_{\mathrm{axL}}\left(\mathrm{cm}^{2} \mathrm{~s}^{-1}\right)$ \\
\hline 3 & 3 & 1 & 40.3 \\
5 & 3 & 1 & 46 \\
6.5 & 3 & 1 & 44 \\
8 & 3 & 2 & 53 \\
3.5 & 4 & 1 & 35 \\
5 & 4 & 2 & 47 \\
6 & 4 & 3 & 58 \\
9 & 4 & 3 & 63 \\
3 & 6 & 3 & 40 \\
4 & 6 & 3 & 43 \\
9 & 6 & 3 & 65 \\
10 & 4 & 4 & 70 \\
10 & 6 & 5 & 72 \\
\hline
\end{tabular}

Table 4. HEF and $Z_{\mathrm{d}} \%$ of EBR at the operating parameters of Figure $7(H=60 \mathrm{~cm})$.

\begin{tabular}{lcccrrr}
\hline$u_{\mathrm{G}}(\mathrm{cm} / \mathrm{s})$ & $u_{\mathrm{Lo}}(\mathrm{cm} / \mathrm{s})$ & $R$ & $u_{\mathrm{L}}(\mathrm{cm} / \mathrm{s})$ & $t_{\mathrm{m}}(\mathrm{s})$ & $Z_{\mathrm{d}}(\%)$ & $\mathrm{HEF}$ \\
\hline 1 & 5 & 0 & 5 & 11.3 & 5.8 & 1.84 \\
3 & 5 & 0 & 5 & 10.1 & 15.8 & 0.81 \\
5 & 5 & 0 & 5 & 9.4 & 21.6 & 0.86 \\
5 & 5 & 2 & 15 & 5.0 & 20.0 & 0.76 \\
\hline
\end{tabular}

column, were correlated well in terms of the operating variables as shown in equations (17)-(19), respectively, with correlation coefficients of $0.927,0.914$, and 0.963 respectively. The ranges of the gas and liquid superficial velocities and the liquid internal recycle ratio were $1 \leq u_{\mathrm{G}} \leq 10 \mathrm{~cm} / \mathrm{s}$, $1 \leq u_{\mathrm{Lo}} \leq 6 \mathrm{~cm} / \mathrm{s}$, and $1 \leq R \leq 5$, respectively.

$$
\begin{aligned}
& E_{1}=0.66088 \times U_{\mathrm{g}}^{0.063787} \times U_{1}^{0.120103} \times R^{0.114528}, \\
& E_{\mathrm{s}}=0.780 u_{\mathrm{G}}^{-0.39} \times u_{\mathrm{Lo}}{ }^{-0.43} \times R^{-0.45}, \\
& D_{\mathrm{axL}}=21.51 u_{\mathrm{G}}{ }^{0.42} u_{\mathrm{Lo}}{ }^{0.01} R^{0.14} .
\end{aligned}
$$

The empirical correlations depict the noticeable effect of the liquid internal recycle ratio, which characterized the EBR, on the objective functions. Table 5 lists Shin's correlations in comparison to the present work's correlations together with the applicable ranges of operating and geometric variables used in present work. As can be observed from the data listed in Table 5, that although the correlation of Shin et al. (2007) highly overestimated the values of liquid holdups and underestimated the values of solid holdups, the gas and liquid superficial velocities still have a positive impact on liquid holdup and have an opposite effect on solid holdup. 


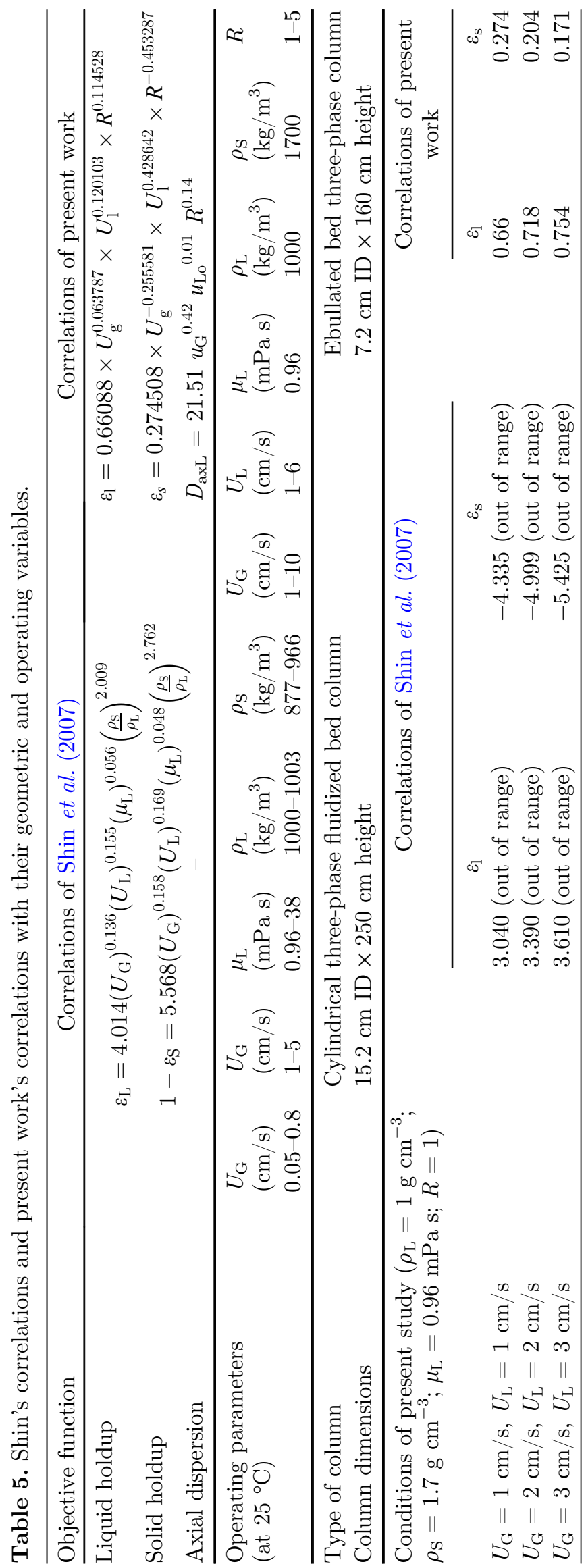

\section{Conclusion}

In present work, hydrodynamics of EBRs was studied in a cold model experimental setup using air-water-solid particles system. Pressure gradient method and RTD technique were used to estimate the individual holdups, and dispersion coefficients in the lab-scale ebullated bed column. The results showed that liquid internal recycle ratio, which characterized the EBRs, has a predominant effect on the individual holdups and dispersion coefficients. Hydrodynamic study revealed that in the free zone of EBR, the dispersion was intermediate between plug flow and complete mixed, and as the total flow, including internal recycle ratio, increased, it became completely mixed flow reactor (with maximum back-mixing). The stagnant zones in EBR did not exceed $20 \%$, even under high flow conditions which was very low when compared to industrial scale reactor operating at high flow rates. Empirical correlations were developed for prediction of phase holdups, bed porosity, and dispersion coefficients with good accuracy. The observations and conclusions made here may not be quantitatively generalized for petroleum fractions because feeds such as heavy oil may give different results due to fluid properties under industrial operating conditions. Thus it is recommended that future studies should be carried out using different fluids to simulate the characteristics of heavy oil such as using $20 \mathrm{wt} \% \mathrm{MgSO}_{4}$ in water (Safoniuk, 1999).

Acknowledgments. Authors are grateful to the Department of Chemical Engineering, University of Technology, Baghdad for providing space and facilities. Thanks are also due to the Petroleum Research \& Development Center, Iraqi Ministry of Oil for assistance.

\section{References}

Chander A., Kundu A., Bej S.K., Dalai A.K., Vohra D.K. (2001) Hydrodynamic characteristics of co-current up flow and down flow of gas and liquid in affixed bed reactor, Fuel 80, 1043-1053.

Essadki A.H., Gourich B., Vial C.H., Delmas H. (2011) Residence time distribution measurements in an external-loop airlift reactor: Study of the hydrodynamics of the liquid circulation induced by the hydrogen bubbles, Chem. Eng. Sci. 66, 14, 3125-3132.

Fogler H.S. (1999) Elements of chemical reaction engineering, 3rd edn., Prentice-Hall, New Jersey.

Froment G.F., Bischoff K.B., Juray D.W. (2010) Chemical reactor analysis and design, 3rd edn., John Wiley \& Sons, New York, NY.

Kim S.D., Kim C.H. (1983) Axial dispersion characteristics of three phase fluidized beds, J. Chem. Eng. Jpn. 16, 172-178.

Kressmann S., Boyer C., Colyar J.J., Schweitzer J.M., Vigui? J.C. (2000) Improvements of Ebullated-Bed Technology for upgrading heavy oils, Oil Gas Sci. Technol. - Rev. IFP Energies nouvelles 55, 397-406.

Levenspiel O. (1999) Chemical reaction engineering, 3rd edn., John Wiley \& Sons Inc., New Jersey.

Parisien V., Pjontek D., McKnight C.A., Wiens J., Macchi A. (2017) Impact of catalyst density distribution on the fluid dynamics of an ebullated bed operating at high gas holdup conditions, Chem. Eng. Sci. 170, 491-500. 
Persson J., Somes N.L.G., Wong T.H.F. (1999) Hydraulics efficiency of wetlands and ponds, Water Sci. Technol. 40, 291-300.

Pjontek D. (2014) Fluid dynamic studies in support of an industrial ebullated bed hydroprocessor, PhD Thesis, The University of Ottawa, Canada.

Pjontek D., Macchi A. (2014) Hydrodynamic comparison of spherical and cylindrical particles in a gas-liquid-solid fluidized bed at elevated pressure and high gas holdup conditions, Powder Technol. 253, 657-676.

Safoniuk M. (1999) Dimensional Similitude and the hydrodynamics of three-phase fluidized beds, PhD thesis in Chemical and Bio-Resource Engineering, The University of British Columbia Vancouver, BC, Canada.

Sánchez O., Michaud S., Escudié R., Delgenès J.P., Bernet N. (2005) Liquid mixing and gas-liquid mass transfer in a threephase inverse turbulent bed reactor, Chem. Eng. J. 114, 1-7.

Sarathai Y., Koottatep T., Morel A. (2010) Hydraulic characteristics of an anaerobic baffled reactor as onsite wastewater treatment system, J. Environ. Sci. China 22, 1319-1326.

Saroha A.K., Khera R. (2006) Hydrodynamic study of fixed beds with cocurrent upflow and downflow, Chem. Eng. Proc. 45, 455-460.

Schweitzer J.M., Kressmann S. (2004) Ebullated bed reactor modeling for residue conversion, Chem. Eng. Sci. 59, 5637-5645.
Shah M., Kiss A.A., Zondervan E., van der Schaaf J., de Haan A.B. (2012) Gas holdup, axial dispersion, and mass transfer studies in bubble columns, Ind. Eng. Chem. Res. 51, 1426814278.

Shin I.S., Son S.M., Kang Y., Kang S.H., Kim S.D. (2007) Phase holdup characteristics of viscous three-phase inverse fluidized beds, J. Ind. Eng. Chem. 13, 971-978.

Silva E.L. (2001) Hydrodynamics characteristics and gas-liquid mass transfer in a three phase fluidized bed reactor, J. Braz. Soc. Mech. Sci. 23, 503-512.

Sivalingam A., Kannadasan T. (2009) Effect of fluid flow rates on hydrodynamic characteristics of co-current three-phase fluidized beds with spherical glass bead particles, Int. J. ChemTech Res. 1, 851-855.

Terashima M., Goel R., Komatsu K., Yasui H., Takahashi H., Li Y.Y., Noike T. (2009) CFD simulation of mixing in anaerobic digesters, Bioresour. Technol. 100, 2228-2233.

Thackston E.L., Shields F.D., Schroeder P.R. (1987) Residence time distribution of shallow basins, J. Environ. Eng. 113, 1319-1332.

Tsai D.D.W., Ramaraj R., Chen P.H. (2012) A method of shortcircuiting comparison, Water Resour. Manag. 26, 2689-2702.

van Gelder K.B., Westerterp K.R. (1990) Residence time distribution and hold-up in a co-current up-flow packed bed reactor at elevated pressure, Chem. Eng. Technol. 13, 27-40. 